\title{
Empreendedorismo Feminino como Sujeito de Pesquisa
}

\author{
Female Entrepreneurship as Subject of Research
}

Iniciativa emprendedora femenina como sujeto de investigación

\author{
Almiralva Ferraz Gomes ${ }^{1}$ \\ Weslei Gusmáo Piau Santana ${ }^{2}$ \\ Uajará Pessoa Araújo ${ }^{3}$ \\ Caroline Miriá Fontes Martins ${ }^{4}$
}

Recebido em 15 de dezembro de 2012 / Aprovado em 30 de junho de 2014

Editor Responsável: João Maurício Gama Boaventura, Dr.

Processo de avaliação: Double Blind Review

\section{RESUMO}

O principal objetivo deste trabalho é estudar a produção sobre o "empreendedorismo feminino", escrutinando e depurando o discurso científico sobre a mulher empreendedora, ao mesmo tempo que investiga o grau de consolidação teórica alcançado na área. Com esse propósito e a partir de uma perspectiva crítica, foram avaliadas pesquisas publicadas em periódicos brasileiros e internacionais a partir da década de 1970, constituindo a presente revisão sistemática do objeto em foco. Não obstante a contribuição de cada estudo afinal, oferecem dados e informaçóes relevantes a respeito da mulher empreendedora -, a maior parte dos trabalhos se limitou a descrever, sem contatar, pequenos segmentos da populaçáo de mulheres empreendedoras e não avançaram na aplicação e desenvolvimento de teorias. Ademais, na maioria das vezes, os estudos foram de natureza quantitativa e empírica e prenderam-se à tentativa de traçar um "perfil" da mulher empreendedora. Poucos foram os estudos que elaboraram uma análise teórica especificamente sobre a temática "gênero". Ao que parece, a preocupação recorrente de muitos trabalhos esteve centrada na estrutura sexuada das organizaçóes e em suas consequências para as atividades empresariais. Com isso, parece ser oportuno trazer a necessidade de se adotar novas lentes para se estudar o fenômeno do "empreendedorismo feminino" para o debate

1. Doutora em Administraçáo pela Universidade Federal de Lavras (UFLA). Professora adjunta do Departamento de Ciências Sociais Aplicadas da Universidade Estadual do Sudoeste da Bahia. [almiralva@gmail.com]

2. Doutor em administração e Professor Adjunto do Departamento de Ciências Sociais Aplicadas da Universidade Estadual do Sudoeste da Bahia. [wpiau@hotmail.com]

3. Doutora em Administração pela Universidade Federal de Lavras (UFLA). Professora Adjunta do Departamento de Ciências Sociais Aplicadas do Centro Federal de Educação Tecnológica de Minas Gerais. [uajara@dcsa.cefetmg.br]

4. Doutora em Administração pela Universidade Federal de Lavras (UFLA). Professora adjunta do Departamento de Ciências Administrativas e Contábeis da Universidade Federal de São João del Rei. [carolfontesmartins@gmail.com] Endereço dos autores: Universidade Estadual do Sudoeste da Bahia - Rua Áureo Tourinho Peçanha, 04 - Quadra E - Bem Querer - B. Candeias, Cep. 45028-670- Vitória da Conquista - BA - Brasil 
- senáo, pelo menos, de estabelecer novos rumos para sua pesquisa.

Palavras-chave: Empreendedorismo. Gênero. Mulher empreendedora.

\section{ABSTRACT}

This paper's main goal is to study the literature produced about "female entrepreneurship", so as to scrutinize and deepen scientific reasoning referring to women entrepreneurs whilst investigating the degree of theoretical consolidation this field of knowledge has achieved. To this end, and from a critical perspective, we assessed research published in Brazilian and international journals from 1970 on, so as to offer a systematic review of the object in focus. Despite the contributions given by previous research - which does, after all, provide us with relevant information and data concerning women entrepreneurs -, most of it merely describes small segments of the female entrepreneur population, and does not advance in applying or developing theories. Moreover, in most cases, research was quantitative and empirical and attempted to draw a "profile" of women entrepreneurs. Few studies specifically carried out a theoretical analysis on the topic "gender". Apparently, the main concern of many of these studies was to focus on the sexual structure of organizations and on its impact upon business activities. Thus, it seems appropriate to use new points-of-view to study the "female entrepreneurship" phenomenon - or, at least, to establish new ideas for investigation.

Keywords: Entrepreneurship. Gender. Women entrepreneur.

\section{RESUMEN}

El objetivo principal de este trabajo es estudiar la literatura sobre la "iniciativa emprendedora femenina”, examinar y depurar el discurso científico sobre la mujer emprendedora además de investigar el grado teórico de consolidación alcanzado en el área. Con este fin, y en una perspectiva crítica, se evaluaron las investigaciones publicadas en revistas brasileñas e internacionales desde los años 1970, formando la presente revisión sistemática del objeto en estudio. No obstante, la contribución de cada estudio - que proporciona información y datos pertinentes sobre la mujer emprendedora - se limita a describir, sin entrar en contacto, pequeños sectores de la población de las mujeres emprendedoras sin avanzar en el desarrollo y aplicación de las teorías. Por otra parte, en la mayoría de los casos, los estudios era empíricos y cuantitativos, y se limitaron a tratar de elaborar un "perfil" de la mujer empresaria. Son pocos los estudios que han sido afectados por el análisis teórico específicamente sobre el tema "género". $\mathrm{Al}$ parecer, la preocupación recurrente de muchos trabajos se ha centrado en la estructura sexual de las organizaciones y su impacto en las actividades empresariales. Por lo tanto, parece adecuado señalar la necesidad de adoptar nuevas lentes para estudiar el fenómeno del "espíritu emprendedor femenino" para el debate, o al menos establecer nuevas direcciones de investigación.

Palabras clave: Emprendimiento. Género. Mujer emprendedora.

\section{INTRODUÇÁO}

A importância das mulheres no empreendedorismo no Brasil pode ser ratificada pelo resultado do Global Entrepreneurship Monitor (GEM). Em 2013, esse estudo revelou que, no Brasil, a proporção de mulheres empreendedoras superou a proporção de homens, apresentando $52,2 \%$ contra $47,8 \%$, respectivamente. A propósito, desde 2002 o referido Relatório já apontava uma aproximação entre as taxas de empreendedorismo dos gêneros feminino e masculino na sociedade brasileira (GEM, 2013a).

Outro aspecto que demonstra a relevância da participação feminina no empreendedorismo brasileiro é essa liderança na abertura de novos negócios no Brasil (GEM, 2013b). Segundo o GEM (2013b), 52\% dos novos empreendedores, aqueles com menos de três anos e meio de atividade, são representados pelas mulheres. Dentre os não empreendedores, a proporção de mulheres que desejam ter seu próprio negócio supera a do gênero masculino, sendo $51,6 \%$ e $48,4 \%$, 
respectivamente (GEM, 2013b). Em relação ao estágio do empreendimento, no Brasil, a taxa de empreendedores iniciais é similar entre homens e mulheres. Não obstante, tanto no gênero feminino como no masculino, a proporçáo de empreendedores por oportunidade é elevada, sendo de $66,2 \%$ a 76,8\%, respectivamente (GEM, 2013a). Portanto, os dados do GEM confirmam a importância e a necessidade de se estudar o fenômeno do "empreendedorismo feminino".

Nesta seção, então, são apresentados o contexto da pesquisa, seu objetivo e o método empregado em sua consecução. Assim é que se aponta que o interesse ou a necessidade das pessoas em desenvolver atividades empresariais tem despertado a diligência dos pesquisadores que almejam compreender tal fenômeno, o que acaba por aumentar o cabedal científico sobre o tema. Essa construção, por sua vez, foi investigada por Ahl (2006), Moore (1990) e Valencia e Lamolla (2005 apud CASSOL, SILVEIRA, HOELTGEBAUM, 2007), que analisaram especificamente a produção acadêmica voltada ao "empreendedorismo feminino". Moore (1990) foi uma das primeiras a desenvolver uma pesquisa dessa natureza. A autora estudou as pesquisas que foram publicadas até a década de 1990 sobre a mulher empreendedora. Em sua investigação, constatou que as publicaçôes sobre o tema eram recentes (à época) e estavam em um estágio inicial de desenvolvimento de paradigmas.

Utilizando o modelo criado por Willian Gartner, Valencia e Lamolla (2005 apud CASSOL, SILVEIRA, HOELTGEBAUM, 2007) estudaram a produção acadêmica em "empreendedorismo feminino" no período de 1990-2004. As pesquisadoras analisaram artigos acadêmicos, livros, anais de eventos e artigos dos principais periódicos da área de empreendedorismo. No ano seguinte, Ahl (2006) tornou público o resultado da análise de discurso de 81 artigos sobre "empreendedorismo feminino" publicados no período de 1982 a 2000 nos quatro principais periódicos internacionais que tratam de empreendedorismo. Nessa pesquisa, a estudiosa notou que os artigos revelavam, apesar de intençóes contrárias, uma tendência de recriar a ideia de que as empresas de mulheres desempenhavam um papel secundário e menos significativo do que as empresas de homens. A constatação de que a pesquisa reproduzia a subordinação feminina levou a pesquisadora a defender a tese de que o estudo sobre mulheres empreendedoras necessitava de novos rumos.

No Brasil, Cassol, Silveira e Hoeltgebaum (2007) analisaram os artigos publicados nos periódicos científicos de administração e de negócios, na base de dados do Institute for Scientific Information (ISI), no período de 1997 a 2006. As pesquisadoras também utilizaram o modelo de Gartner e, assim como Valencia e Lamolla (2005 apud CASSOL, SILVEIRA, HOELTGEBAUM, 2007), concluíram que a produção sobre "empreendedorismo feminino" centrava-se nas dimensôes individual e ambiente.

Pretende-se desse modo, aqui, complementar os passos desses precursores supracitados no intuito de se evidenciar o estágio em que se encontram tais pesquisas e contribuir para o aumento do conhecimento e da disseminação dos resultados sobre o assunto, ao se direcionar para o objetivo de estudar a produção sobre o "empreendedorismo feminino", escrutinando e depurando o discurso científico sobre a mulher empreendedora, ao mesmo tempo que se investiga o grau de consolidação teórica alcançado na área.

Essa revisão de literatura resultou da consulta inicial a dois repositórios: o Portal de Periódicos da Coordenação de Aperfeiçoamento de Pessoal de Nível Superior (Capes) e os anais dos Encontros Nacional de Pós-graduação em Administração (Enanpad) de 1999 a 2008. O Portal permite o acesso a diversas revistas que tratam do empreendedorismo e publicaram artigos sobre "empreendedorismo feminino", e os Enanpad foram admitidos por sua relevância, na suposição de representar, em certa medida (não quantificável), a produção nacional, em adição aos trabalhos divulgados em periódicos brasileiros que já faziam parte do Portal da Capes. As expressôes "empreendedorismo" e "empreendedorismo feminino” e os vocábulos correspondentes em inglês foram empregados como termo de busca. Adicionalmente, foi utilizada a análise de citaçôes cruzadas e as recomendaçôes da técnica de 
amostragem snowball (BIERNACKI, WALDORF, 1981), de tal forma que foi considerado como relevante o trabalho citado por artigos já previamente classificados como relevantes, tanto mais quanto mais citaçôes o artigo em análise recebesse. Por fim, efetuou-se o refino da coletânea (262 itens pré-selecionados) pelo estudo dos resumos e da bibliografia. Isso reduziu a seleção inicial para uma amostra constituída por 117 artigos científicos: 21 nacionais e 96 internacionais. Tal conjunto apontou a proeminência do periódico internacional Entrepreneuship: Theory and Practice e Frontiers of Entrepreneurship Research, que apresentava a maior quantidade de artigos publicados sobre a temática investigada. Os periódicos International Journal of Entrepreneurial Behavior \& Research, International Entrepreneurship and Management Journal, Journal of Business Venturing, Entrepreneurship Management, Equal Opportunities International, Journal of Small Business Management e Women in Management Review também se destacaram. Os Enampad supriram 16 trabalhos, que, por sua vez, faziam referência a uma produção nacional publicada nos periódicos Revista de Administração de Empresas (RAE), Organização e Sociedade (O\&S), Psicologia em Estudo, Psicologia \& Sociedade e Revista Perspectiva Contemporânea. Uma recente atualização da revisão de literatura, no Portal de Periódicos Capes, também apontou uma produção científica sobre o tema nos periódicos Revista de Administração Contemporânea (RAC), Revista de Administração (Rausp), Revista de Administração Pública (RAP), Cadernos Ebape, Psicologia Clinica, Revista de Sociologia e Economia Rural e Revista de Empreendedorismo e Gestão de Pequenas Empresas. Essa atualização passou a fazer então parte do corpus, constituindo, assim 126 trabalhos, que receberam o tratamento da metassíntese qualitativa (WALSH, DOWNE, 2005), de modo a se pesquisar o tipo de abordagem adotada, a natureza da análise dos estudos, o método adotado, as técnicas mais utilizadas e os principais pesquisadores e seus vínculos profissionais. Com relação às publicações que foram realizadas pós década de 1990, tendo em vista a quantidade, se comparada às décadas anteriores, levou-se em conta também as áreas temáticas que mais se apresentaram no período estudado. Desse modo, a seção que trata da produção realizada pós anos 90 está organizada conforme os temas que mais se apresentaram no referido período. O produto de tal estudo é apresentado em três seçóes, separado cronologicamente e seguido de uma última seção contendo as reflexôes finais.

\section{OS PRIMEIROS ESTUDOS DO EMPREENDEDORISMO FEMININO}

O estudo sobre mulheres empreendedoras remonta à década de 1970 . Até então apenas os homens eram objeto de pesquisa nos estudos sobre empreendedorismo (AHL, 2006). Um dos primeiros trabalhos sobre "empreendedorismo feminino" que a presente pesquisa levantou foi o de Schwartz (1976). No artigo, a autora abordou aspectos relacionados à motivação, características de personalidade e dificuldades enfrentadas por mulheres empreendedoras. Schwartz (1976) concluiu, na ocasiāo, que os motivos que levavam mulheres a montar seu próprio negócio eram semelhantes aos dos homens. Além disso, ambos tinham "qualidades empreendedoras" parecidas. Suas diferenças eram mínimas. A pesquisadora detectou, no entanto, que as mulheres enfrentavam mais barreiras que impediam o sucesso de suas organizaçôes, principalmente em função das dificuldades de obtenção de crédito.

No final daquela década, Decarlo e Lyons (1979) publicaram o resultado de uma investigação realizada com 122 mulheres. Os pesquisadores descreveram o perfil do grupo de empresárias e compararam esse perfil com os de outros grupos de mulheres. De natureza quantitativa, os dados forneceram informação sobre o "perfil" das mulheres empresárias e contribuíram para pesquisas que foram realizadas adiante. Não obstante a constatação de que as mulheres empreendedoras diferenciavam-se das mulheres em geral, os autores concluíram que existia a necessidade de pesquisa adicional para que se chegasse a conclusóes mais úteis.

A presente pesquisa levantou uma pequena quantidade de artigos publicados na década de 1970. No entanto, os anos 1980, se comparados à década anterior, despontaram como um 
período em que, pelo menos quantitativamente, as pesquisas sobre "empreendedorismo feminino" cresceram. Esse aumento pode ser explicado, pelo menos em tese, pelo crescimento da participação feminina no mercado de trabalho, não só como empregada, mas como empregadora e dona de seu próprio negócio. O presente estudo revelou que a produção acadêmica internacional sobre o tema limitou-se ao hemisfério norte. Robert Hisrich e Candida Brush são, por exemplo, estudiosos que continuam investigando o fenômeno, ora realizando estudos sozinhos, ora entre eles ou com outros parceiros, inclusive de outras instituiçóes e de outros países.

No início da década de 1980, Hisrich e O'Brien (1981) previram que, mesmo quando a presença das mulheres na atividade empreendedora ainda não fosse significativa, a participação delas cresceria em quase todas os setores. Ao pesquisar 21 mulheres empresárias, Hisrich e O’Brien (1981) detectaram que elas tinham dificuldades relacionadas com o acesso a linhas de crédito, a obtenção de garantias e a superação de uma imagem negativa a respeito da mulher. Os resultados da pesquisa demonstraram que os problemas enfrentados estavam relacionados ao tipo de negócio e não ao grau de escolaridade ou nível de experiência das respondentes. Em 1984, Hisrich e Brush, considerando que pouco se sabia sobre as mulheres empresárias, realizaram uma pesquisa com 468 empresárias e descreveram seu perfil, sua motivação, suas habilidades, os problemas e as características de seus negócios.

Ainda na mesma década, Hisrich e Brush (1987) analisaram os resultados de um estudo longitudinal realizado com mulheres empresárias e, mais uma vez, investigaram suas características pessoais, práticas familiares, habilidades gerenciais, disposição para correr riscos, problemas enfrentados e índice de crescimento empresarial. Assim como Hisrich e Brush (1984, 1987), Joos (1987) acreditava que a atuação feminina na atividade empreendedora crescia, embora pouco se soubesse sobre ela. Assim, explicitou, numericamente, a ascensão feminina na condição de empresária, nos Estados Unidos, entre meados da década de 1970 e meados da década de 1980, creditando parte do crescimento ao estímulo dado pelo governo do presidente Jimmy Carter, que criou programas para apoiar mulheres empresárias: havia a compreensão de que seus empreendimentos impactavam, positivamente, sobre a economia norte-americana.

As pesquisas, porém, não se limitaram aos Estados Unidos. No Reino Unido, Watkins e Watkins (1983) apresentaram o resultado de uma pesquisa realizada com mulheres empreendedoras e compararam a experiência de homens e mulheres. Os autores concluíram que as mulheres empreendedoras, em função de fatores involuntários e de decisão consciente, restringiam-se a atuar em áreas estereotipicamente femininas. $\mathrm{Na}$ visão dos autores, à medida que a sociedade aceitasse de fato a presença feminina no mercado de trabalho, exercendo a função de empresária, e proporcionasse condiçóes igualitárias a elas, as mulheres atuariam em qualquer segmento empresarial. Watkins e Watkins (1983) indicaram que as diferenças entre homens e mulheres não eram necessariamente de ordem biológica, mas de caráter social. Buttner e Rosen (1988) levantaram a discussão a respeito do poder e da influência dos estereótipos de gênero no meio empresarial. Os pesquisadores investigaram se mulheres empreendedoras eram vistas em termos de estereótipos sexuais no processo de tomada de empréstimo em instituições de financiamento e concluíram que os agentes financeiros tinham uma compreensão generalizada e preconceituosa de que a mulher teria menos chance de lograr êxito se comparada ao homem, uma vez que náo possuiriam os "atributos" necessários para ser empreendedora de fato.

Ainda no Reino Unido, Carter (1989) publicou o resultado de uma investigação realizada com mulheres empreendedoras e considerou que seus empreendimentos possuíam um desempenho e uma dinâmica peculiar a sua condição. De certa forma, ela explicou que as diferenças entre homens e mulheres se davam em função de um comportamento, motivação e ambição pessoais diferenciados, inclusive porque as mulheres possuíam um critério particular, que não era meramente econômico, para avaliar o sucesso. No mesmo 
caminho, nos Estados Unidos, Wilkens (1989:15) também defendeu a tese de que as mulheres precisavam aceitar suas "forças tipicamente femininas e reconhecer", que tais forças proporcionariam uma base sólida para o desenvolvimento e sucesso de suas carreiras como empreendedoras. A compreensão de Carter (1989) e Wilkens (1989) a respeito das diferenças passava mais por questôes de cunho pessoal, ao contrário do que sugeriram Buttner e Rosen (1988).

Outros estudos buscaram conhecer a mulher empreendedora comparando-a ao homem empreendedor. $\mathrm{O}$ estudo comparativo, de fato, sempre esteve presente na produção acadêmica sobre o tema (CARTER, 1989; HOLMQUIST, SUNDIN, 1989; SMITH, MCCAIN, WARREN, 1982; STEVENSON, 1986; WATKIN, WATKINS 1983). Aldrich, Reese e Dubini (1989), inclusive, pesquisaram redes de empreendedores e empreendedoras nos Estados Unidos e na Itália. Não observaram diferenças expressivas entre os países. Contudo, identificaram diferenças significativas entre as redes compostas por homens e aquelas constituídas por mulheres. Ressalvando a pequena quantidade de mulheres inseridas em redes pessoais, os pesquisadores verificaram disparidades substanciais entre os "mundos" feminino e masculino. Inspirados no trabalho de Aldrich, Reese e Dubini (1989), Cromie e Birley (1992) desenvolveram um estudo similar no norte da Irlanda. As pesquisadoras chegaram à conclusão de que as mulheres, quando comparadas aos homens, são menos ativas nas redes, desenvolvem redes menos densas, estão mais inclinadas a discutir com outras mulheres e consideram os membros da família as pessoas mais importantes de sua rede de contatos.

O presente estudo detectou que há um predomínio, até então, na busca de diferenças entre homens e mulheres empreendedoras por meio de dados demográficos, familiares, ocupacionais e educacionais. Em outras palavras, as pesquisas também adotaram uma abordagem mais quantitativa. Todavia, identificaram-se trabalhos como o de Neider (1987), que tentou combinar entrevista semiestruturada com teste psicológico e observação, a fim de investigar a personalidade, características demográficas e características organizacionais do empreendimento de 52 mulheres na Flórida. Apesar de unir diversas técnicas de pesquisa, ela também acabou traçando um "perfil psicológico" da mulher empreendedora. A pesquisadora detectou que predominavam nessas empreendedoras certas "características", como alto nível de energia, persistência e habilidade para influenciar os outros.

A revisão de literatura realizada até aqui revela que houve uma primazia de metodologias com abordagem quantitativa. Em outras palavras, os artigos analisados permitem afirmar que a década de 1980 foi marcada por estudos, na maioria das vezes, quantitativos e empíricos que tentaram caracterizar, ou melhor, traçar um "perfil" da mulher empreendedora. Tal é que Sexton e Kent (1981), no intuito de identificar características psicológicas que distinguissem as mulheres executivas das mulheres empresárias, compararam o comportamento de 45 executivas e 48 empresárias, concluindo que elas possuíam mais semelhanças do que diferenças. No ano seguinte, Smith, McCain e Warren (1982) publicaram o resultado de uma pesquisa realizada com 76 empreendedores em São Francisco, nos Estados Unidos. Os autores classificaram os empreendedores em crafts-oriented o opportunistic. Comparadas aos homens, as mulheres demonstraram uma tendência a um comportamento e atitudes mais oportunistas.

Como precursores, esses estudos introduziram a mulher no debate sobre o empreendedorismo e apresentaram dados preliminares a respeito da mulher na condição de empresária e empreendedora em vários países. As contribuições dessas pesquisas tenderam, fundamentalmente, a formular estudos normativos de natureza empírica destinada a identificar características demográficas e de personalidade das mulheres e, inclusive, a traçar seu "perfil comportamental". Em sua base, esses estudos prenderam-se à identificação e à descrição de características daquilo que seria uma mulher empreendedora, buscando em sua "essência” determinados atributos. Conclui-se então que, com relação à década de 1970 e 1980, a produção científica internacional ainda ficou 
presa à visão do determinismo biológico - que coloca o sexo como o elemento desencadeador das diferenças - e pouco trouxe para o debate a atuação do contexto sociocultural na construção dos significados de ser homem e de ser mulher. Embora não se esteja fazendo aqui nenhum tipo de generalização, as pesquisas realizadas na década subsequente não se comportaram de forma tâo diferente.

\section{OS AVANÇOS NA DÉCADA DE 1990}

Os anos 1990 iniciaram-se com pesquisas que foram além dos Estados Unidos e da Europa. A Ásia foi objeto de interesse de Chew e Yan (1991) e Hisrich e Fan (1991). Os primeiros exploraram o caso da República Popular da China, que sofreu um crescimento acentuado no número de empresárias a partir de 1978. Os últimos investigaram a experiência de mulheres empresárias em Cingapura, com ênfase nos padróes de mudança estabelecidos e vivenciados por elas. Muito embora os estudos fossem inusitados, tendo em vista que a empresária asiática ainda não tinha sido objeto de investigação, ambas as pesquisas restringiram-se a traçar um "perfil" das mulheres empresárias dessas regióes.

Apesar de partir de uma proposta muito similar àquelas que tinham sido desenvolvidas até então, o estudo de Lee-Gosselin e Grisé (1990) é usualmente citado entre aqueles que levantaram e analisaram a produção científica sobre o tema. Isso porque os resultados do estudo, de acordo com os autores, representaram uma adaptação inovadora à demanda profissional, familiar, social e pessoal, pois desafiaram as definiçôes existentes sobre empreendedorismo. Os pesquisadores, inicialmente, aplicaram questionário junto a 400 mulheres (gerentes e/ou donas do próprio negócio) na cidade de Quebec e, posteriormente, entrevistaram detalhadamente 75 delas, com o intuito de conhecer seus "traços" pessoais e as características de suas organizações, suas experiências anteriores, seus critérios para avaliar o sucesso e suas visóes a respeito do futuro de suas empresas. A pesquisa revelou que as mulheres preferiam um modelo de negócio pequeno e estável a fim de preservar sua qualidade de vida e náo comprometer a vida familiar.

O trabalho de Sexton e Bowman-Upon (1990) não se restringiu à descrição e buscou avançar para uma contribuição senão teórica ao menos crítica e reflexiva. Por meio de um estudo comparativo entre gêneros e do estabelecimento de "características psicológicas" de empreendedores, os pesquisadores estudaram 105 mulheres e 69 homens nos Estados Unidos. Os estudiosos concluíram que homens e mulheres possuíam comportamento similar em vários aspectos. Os autores verificaram que até existiam algumas diferenças gerenciais relacionadas ao gênero. No entanto, as poucas diferenças existentes eram usadas abusivamente com fins de estereotipagem sexual.

Ao utilizar análise de regressão múltipla, Leahy e Eggers (1998) detectaram que as mulheres empreendedoras eram mais focadas nas tarefas, ao contrário do que se imaginava, o que contrariava a crença de que as mulheres eram mais voltadas para as pessoas. A pesquisa de Leahy e Eggers (1998) sugeriu que muitos estudos podiam estar carregados de estereótipos que apontavam nas mulheres determinadas habilidades como se fizessem parte de sua "essência".

Algumas pesquisas concluíram que homens e mulheres, não obstante suas diferenças, possuíam comportamentos similares (FAGENSON, 1993; SCHWARTZ, 1976; SEXTON, BOWMAN-UPON, 1990; SEXTON, KENT, 1981), ao passo que outros trabalhos afirmaram que eles eram "naturalmente" diferentes. O trabalho de White e Cox (1991), como muitos (CROMIE, BIRLEY, 1992; ALDRICH, REESE, DUBINI, 1989; CARTER, 1989; LEE-GOSSELIN, GRISÉ, 1990; NEIDER, 1987; SMITH, MCCAIN, WARREN, 1982), defendeu que as mulheres eram diferentes dos homens. Eles creditaram a diferença entre homens e mulheres ao que denominaram independence of thought. Ou seja, argumentaram que, essencialmente, as mulheres, além de possuir identidade de gênero, portavam um estilo criativo e político próprios. Tais características influenciariam o comportamento feminino. 
Fasci e Valdez (1998) detectaram que os empreendimentos geridos por homens possuíam uma lucratividade maior do que aqueles geridos por mulheres. As diferenças, portanto, estavam no resultado da empresa em função de variáveis conjunturais e contingenciais. Coleman (1998) não verificou discriminação nas instituições financeiras no processo de tomada de empréstimo quanto ao gênero, mas sim quanto ao porte do empreendimento e a seu tempo de existência.

Apesar de estudos tratarem de diferenças entre os gêneros, Fisher, Reuber e Dyke (1993) argumentaram que as pesquisas realizadas até então não conseguiam identificar e, sobretudo, explicar as diferenças entre empreendedoras e empreendedores. $\mathrm{Na}$ visão das autoras, as teorias feministas podiam contribuir para a compreensão das pesquisas que estudavam mulheres empreendedoras. $\mathrm{Na}$ ocasiáo, elas trabalharam com duas perspectivas: a do feminismo liberal e a do feminismo social. Por um lado, o feminismo liberal admitia que as mulheres estivessem em desvantagem em relação aos homens, em função da discriminação e/ou de fatores contingenciais que as privaram de recursos essenciais, como educação e experiência na área de negócios. Por outro, o feminismo social reconhecia que existiam diferenças entre homens e mulheres. No entanto, tais diferenças eram fruto de um processo de socialização diferenciado que cada um vivenciava ao longo de sua vida. $\mathrm{O}$ artigo representou um avanço na produção acadêmica sobre o tema porque não se limitou a apenas apresentar resultados, mas sugeriu a adoção das lentes da teoria feminista para interpretar o fenômeno do "empreendedorismo feminino".

Um pouco mais tarde, Hisrich et al. (1997) apoiaram-se nas visóes teóricas do feminismo liberal e do feminismo social e investigaram a existência de fatores que interferiam no desempenho de empreendimentos geridos por mulheres, uma vez que, até então, os estudos buscavam basicamente identificar esses fatores a partir de análises meramente quantitativas (ALLEN, CARTER, 1996; CARTER, 1989). Os pesquisadores concluíram que tanto o feminismo social quanto o liberal se aplicavam ao contexto do empreendedorismo. No entanto, eles sugeriram que o "empreendedorismo feminino" fosse estudado separadamente da teoria de empreendedorismo, tendo em vista que variáveis internas e externas demonstraram a existência de similaridades e diferenças de gênero.

O estudo de Fagenson (1993) também trouxe para o debate questóes que Buttner e Rosen (1988), Sexton e Bowman-Upon (1990) e Watkins e Watkins (1983) também já haviam sinalizado sobre a existência da estereotipagem de gênero no mundo empresarial. Não obstante a sugestão de vários estudos de que o tipo de indivíduo que se tornava empresário era, psicologicamente, diferente daquele que se tornava gerente e de que as mulheres também eram diferentes, Fagenson (1993), ao comparar o sistema de valores pessoais de 255 homens e mulheres gerentes e empreendedores, detectou que o gênero dos indivíduos, ao contrário da carreira, pouco influenciava seus sistemas de valores.

Dolinsky, Caputo e Pasumarty (1994) introduziram e combinaram os elementos cor e gênero no estudo do empreendedorismo na década de 1990. Os autores constataram que as mulheres negras estavam mais distantes do empreendedorismo, se comparadas às mulheres brancas. Eles analisaram a diferença nos padrôes longitudinais das taxas de emprego desses grupos e concluíram que a dificuldade histórica de acesso a crédito devia ser um dos motivos que, potencialmente, explicaria a baixa participação da mulher negra na condição de empresária. Mais recentemente, outras pesquisas têm sido realizadas com a finalidade de estudar o gênero, a raça e a cor dos indivíduos que empreendem (PIO, 2007a; 2007b; FULLER-LOVE, LIM, AKEHURST, 2006; LERNER, MENAHEM, HISRICH, 2005).

Zapalska (1997), ao pesquisar um total de 150 empreendedores e empreendedoras nos três maiores centros urbanos da Polônia, investigou se as empresárias possuíam as características empreendedoras requeridas para apresentar desempenho efetivo como empreendedoras. Os resultados mostraram que as empreendedoras possuíam as "características" requeridas para o "sucesso" como agressividade, positividade, determinação, habilidades de comunicação, habilidades de liderança, autonomia, ambição, responsabilidade, inovação, 
criatividade, tendência para correr riscos, prontidão para a mudança, baixa necessidade de apoio e falta de sentimentalismo. Ou seja, as mulheres empreendedoras apresentavam as "características" tidas como masculinas e femininas identificadas na literatura como de empreendedores prósperos. Zapalska (1997), no entanto, ressaltou que numerosos estudos associavam mais frequentemente as "características do empreendedor de sucesso" com o comportamento masculino, sugerindo que as mulheres só teriam sucesso como empreendedoras se exibissem essas características, e sobretudo as apontavam como mais frágeis e mais emocionais do que os homens. A pesquisadora verificou que as mulheres polonesas investigadas demonstraram possuir o "perfil" e as habilidades empreendedoras necessárias ao sucesso e eram semelhantes aos homens em relação a aspectos motivacionais e características pessoais. Logo, concluiu que, independentemente de gênero, um empreendedor atingiria o êxito se possuísse as "características" requeridas para empreender com sucesso.

O caráter comparativo, descritivo e quantitativo predominou também na década de 1990 entre as pesquisas sobre a mulher empreendedora. No entanto, alguns pesquisadores tentaram não se prender apenas a pesquisas de cunho quantitativo. Stevenson (1990), por exemplo, argumentou que um dos problemas metodológicos associados com as pesquisas a respeito de mulheres empreendedoras era o fato de seus métodos concentrarem seu interesse nos aspectos quantitativos dos fenômenos, negligenciando as explicações sobre os eventos dentro de situaçóes concretas. Por conta disso, propôs a adoção de métodos qualitativos de investigação, pois entendia que a melhor maneira de desvendar as relaçóes na esfera da mulher empreendedora era entrevistá-la e deixá-la explanar sobre seus relacionamentos.

Dessa forma, a década de 1990 trouxe resultados e dados ricos a respeito da situação feminina no empreendedorismo, o que proporcionou maior conhecimento a respeito da mulher empreendedora. Todavia, ainda se verificava uma tendência em se repetir estereótipos femininos que apontavam para a existência de características peculiares à gestão feminina. Ou seja, estudos foram desenvolvidos em torno da ideia de que as mulheres possuíam comportamentos gerenciais diferenciados em função de uma "natureza" feminina diferenciada. Apesar de se verificar, desde a década de 1970, passando pela de 1980 e 1990 e chegando aos dias atuais, publicações que concluíram que as mulheres eram "essencialmente" diferentes dos homens, já se constatavam, ainda que timidamente, pesquisas que identificavam mais similaridades do que diferenças entre empreendedores e empreendedoras e, sobretudo, estudos que creditavam as diferenças à maneira como homens e mulheres são formados, criados e educados na sociedade. Ou seja, já se introduzia a noção de construção social nas publicações acadêmicas sobre o tema e já era possível se identificar estudos que escapavam à tendência de um discurso naturalizado.

\section{A PRODUÇÃO ACADÊMICA SOBRE EMPREENDEDORISMO FEMININO PÓS 1990}

O volume da produção acadêmica, principalmente internacional, que trata do "empreendedorismo feminino", cresceu substancialmente pós anos 1990. Assim como não foi possível fazer com a década de 1980 e 1990, com essa década seria mais difícil ainda, senão impossível, apresentar, aqui, uma revisão que contemplasse toda a produção científica do período. Mesmo fugindo a qualquer forma de reducionismo, não há como ignorar que algumas temáticas foram mais abordadas pela literatura especializada, não obstante a peculiaridade de cada trabalho. Temas relacionados à competência e ao comportamento da empreendedora, ao processo de criação de suas empresas e ao acesso a crédito e capital de risco estão entre os mais investigados. No entanto, também foram identificados artigos que trataram de questôes relacionadas a representaçôes sociais e identidade, a fatores que implicam o sucesso/fracasso do empreendimento, a grupos minoritários, a formação e educação empreendedora, a políticas públicas, entre outros. Desse modo, esta seção irá apresentar o resultado das análises levando-se em conta as áreas temáticas identificadas. 
O presente estudo também verificou que a publicação da produção nacional, nos principais periódicos nacionais e nos anais de um dos eventos mais respeitados da área de administração, no Brasil, deu-se apenas a partir da década de 1990. Um dos artigos que inaugurou a produção acadêmica brasileira, com projeção nacional, foi o de Machado (1999), apresentando as tendências do comportamento gerencial da mulher empreendedora baseadas na compilação de estudos anteriores. Especificamente, no Brasil, verificou-se que a maior parte dos estudos é realizada por pesquisadoras vinculadas a instituições das regióes Sul e Sudeste do Brasil. Ademais, as publicaçóes brasileiras investigam, na maioria das vezes, o contexto nacional (STROBINO, TEIXEIRA, 2014; CRAMER et al., 2012, JONANTHAN, 2011; VALE, SERAFIM, TEODÓSIO, 2011; LIMA, FREITAS, 2010; MACHADO, WETSEL, RODRIGUES, 2008; JONATHAN, SILVA, 2007; FERREIRA, GIMENEZ, RAMOS, 2005; LINDO et al., 2004; JONATHAN, 2003; MACHADO, 2001).

O conjunto dos artigos que aborda as competências e o comportamento do empreendedor envolve trabalhos que tratam das características presentes no modo de gerenciar de mulheres. Alguns se restringem a apresentar um perfil da mulher empreendedora (COOK, BELLIVEAU, LENTZ, 2007; MCCLELLAND et al., 2005; SERNA, 2002; STILL, WALKER, 2006; TAKAHASH, GRAEFF, 2005; WALKER, WEBSTER, 2006). Na apresentação do "perfil" empreendedor feminino, apontam atributos como sensibilidade, habilidade para trabalhar em equipe $\mathrm{e}$ intuição como inerentes às mulheres (CANTZLER, LEIJON, 2007; KYRO, 2001; ORSER, RIDING, MADILL, 2002; RENTSCHLER, 2007). Esses pesquisadores não somente partem da noção de que as mulheres possuem em sua "essência" tais qualidades como atestam, teórica e/ou empiricamente, seu posicionamento.

Já Welch, Welch e Hewerdine (2008) adotam a lente dos estudos de gênero para compreender o comportamento empreendedor de mulheres. Na mesma proporção, são poucos aqueles que não chegam a conclusóes de cunho essencialista, considerando as diferentes experiências de socialização feminina (MANOLOVA et al., 2007). Aliás, Manolova et al. (2007), ao contrário de muitos estudos que ficaram na mera apresentação de dados quantitativos e muito pouco os discutiram, debateram intensamente o resultado dos testes estatísticos com 544 empreendedores e empreendedoras na Bulgária. No entanto, várias pesquisas já não observaram diferenças significativas de comportamento e competências entre homens e mulheres, apesar de destacar que o desempenho empresarial, a disponibilidade para correr riscos e as escolhas estratégicas podiam ser associados aos valores, às experiências e aos traços pessoais dos indivíduos (RODRÍGUEZ, SANTOS, 2009; BOOHENE, SHERIDAN, KOTEY, 2008; WAGNER, 2007; MENZIE et al., 2006; FERREIRA, GIMENEZ, RAMOS, 2005; MACHADO, JANEIRO, MARTINS, 2003; PELISSON et al., 2001; GIMENEZ et al., 2000). Algumas pesquisas, como a de Verheul (2003), chegaram a constatar que, ao contrário do que se pressupunha, as empresas geridas por mulheres eram mais orientadas para o controle do que as geridas pelos homens, ou ainda que as mulheres empreendedoras davam menos espaço para participaçáo e tomada de decisóes aos empregados e centralizavam a estrutura organizacional.

Ao pesquisarem o comportamento empreendedor, Diegues-Castrillon et al. (2012) constataram, na região da Galícia, a influência do gênero na decisão de mulheres em diversificar atividades no âmbito rural para o turismo. A pesquisa revelou a coexistência de dois fenômenos no âmbito rural: a execução de novas propostas e medidas de desenvolvimento e reestruturação rural e a incorporação das mulheres na esfera econômica, social e laboral. Para as pesquisadoras, as mulheres consideravam o aspecto econômico como mais motivador para empreenderem no turismo rural, ao contrário dos homens. As mulheres orientavam-se, na escolha pelo empreendimento turístico rural, pela possibilidade de geração de renda que garantisse a sobrevivência financeira. Tal constatação é contrária ao que é apontada pela literatura (CARTER, 1989; KYRO, 2001), a qual defende a prioridade feminina de objetivos 
do âmbito social ou familiar frente os objetivos econômicos.

Conhecer os motivos e outros fatores que contribuem para a decisão feminina de implantar seu próprio negócio foi o objetivo de muitos pesquisadores nacionais e, predominantemente, estrangeiros. No caso brasileiro, foram identificados os artigos de Machado et al. (2003) e Rodrigues e Wetzel (2003). Machado et al. (2003) investigaram o processo de criação de empresas por mulheres no Brasil, na França e no Canadá e constataram que a realizaçáo pessoal, a visão de oportunidade de mercado e a insatisfaçáo no emprego estavam entre os principais motivos que levavam as empresárias a criar uma empresa. Rodrigues e Wetzel (2003), ao pesquisarem as motivaçóes de empreendedoras que atuavam em serviços de bufê, indicaram que as razóes que guiaram essas mulheres a optar por negócios ligados às atividades de cozinha estavam relacionadas a interesses desenvolvidos ainda na infância e no ambiente familiar. Ao contrário do que se poderia esperar, tal opção não foi relacionada à ideia de que elas possuíam habilidades "naturais" para cozinhar.

Os artigos que trataram do processo de criação de empresas também investigaram se, no procedimento de abertura, pesou a questão da oportunidade (RODRÍGUEZ, SANTOS, 2009; DETIENNE, CHANDLER, 2007; DHALIWAL, KANGIS, 2006), se a necessidade foi mais relevante (WALKER, WEBSTER, 2007; GRAY, FINLEY-HERVEY, 2005; VERHEUL, THURIK, 2003), se fatores como realização pessoal pesaram mais do que aspectos econômicos (KYRO, 2001) ou ainda se os pais influenciaram nas decisôes de seus filhos (KIRKWOOD, 2007). Alguns desses artigos pesquisaram as razôes que levaram mulheres a saírem de seus empregos e optar pela implantaçáo de um negócio próprio (KEPHART, SCHUMACHER, 2005; TERJESEN, 2005).

As pesquisas que trataram de assuntos relacionados à capital de risco e financiamento, na maioria das vezes, investigaram os motivos pelos quais as mulheres contratavam menos empréstimo do que os homens. Alguns estudos, por um lado, desmentiram a crença de que havia discrimina- ção no processo de liberação de crédito bancário (WILSON et al., 2007); outras pesquisas, por outro lado, identificaram ora a existência de discriminação (MARLOW, PATTON, 2005), ora a modesta diferença na ênfase dada a determinados critérios de avaliação dos pedidos de empréstimo, quando os agentes financeiros eram indivíduos do sexo feminino ou do sexo masculino (CARTER et al., 2007). A propósito, a pesquisa de Carter $e t$ al. (2007) é um exemplo bem sucedido da adoção conjunta da pesquisa qualitativa e quantitativa. Os autores combinaram métodos experimentais com metodologias qualitativas e apresentaram a visão do agente financeiro com relação ao financiamento ao empreendedorismo.

De fato, boa parte desses estudos verificou que as mulheres obtinham menos recursos financeiros de instituiçôes bancárias do que os homens. Porém, isso acontecia porque elas buscavam menos capital externo do que eles, e não por discriminação de gênero - como manifesto por um grupo significativo de pesquisas (WILSON et al., 2007; ORSER, RIDING; MANLEY, 2006; BJÖRNSSON, ABRAHA, 2005; BRUIN, FLINT-HARTLE, 2005). Orser, Riding e Manley (2006), inclusive, puderam alertar aqueles que estudam o assunto a respeito da importância de se adotar métodos de pesquisa mais consistentes para se evitar a transmissão de falsas impressões. Aliás, alguns estudos consideraram que os empreendimentos masculinos se destacavam se comparados aos femininos, porque as mulheres pouco buscavam capital externo (ALSOS, ISAKSEN, LJUNGGREN, 2006; WATSON, 2002), inclusive porque eram mais avessas a risco (CARTER, 2002). Em se tratando de acesso a capital de risco, Becker-Blease e Sohl (2007) e Harrison e Mason (2007) simplificaram a complexidade do assunto quando concluíram em suas investigaçôes, cada um a seu modo, que as mulheres recebiam pouco capital de risco porque procuravam pouco por esse tipo de capital e quando procuravam preferiam capital de risco oriundo de investidoras, ao passo que os homens, de investidores. Gatewood et al. (2003) propuseram um modelo conceitual que considerava que o potencial dos empreendimentos femininos estava 
relacionado à busca de capital externo. $\mathrm{Na}$ visão das autoras, tal modelo poderia oferecer uma direção para as futuras pesquisas sobre o tema, uma vez que até então os estudos eram unilaterais e de natureza basicamente empírica.

A discussão a respeito dos fatores que interferem no desenvolvimento e no desempenho das empresas também foi objeto de estudo de pesquisadores brasileiros e estrangeiros. As pesquisas detectaram que os problemas que comprometiam o êxito do empreendimento estavam relacionados a dificuldades financeiras, falta de capacitação empreendedora e gerencial, restriçóes de mercado e distribuição, limitação de oportunidades e de participação em redes, baixo apoio governamental e institucional, ausência de know-how e de mecanismos de integração, dificuldades para equilibrar as demandas profissionais, pessoais e familiares e até de corrupção em alguns países (SINGH, BELWAL, 2008; JONATHAN, SILVA, 2007; SILVA, 2006). Lima e Freitas (2010) pesquisaram o desempenho de negócios do setor informal a partir de cinco dimensóes para a compreensão da dinâmica empreendedora: personalidade empreendedora, recursos pessoais, ambiente, atividades organizacionais e gênero. Esses autores investigaram dois modelos multidimensionais. No primeiro modelo, foram avaliadas as variáveis personalidade empreendedora, recursos pessoais, ambiente e atividades organizacionais. No modelo multidimensional II, foi considerada a variável gênero, além das variáveis do modelo I. Segundo os autores, no primeiro modelo multidimensional, a dimensão atividades organizacionais apresentou a maior relevância. Por seu turno, ao incorporar a variável gênero, a classificação de importância modificou-se e o fato de ser homem ou mulher passou a ser a maior fonte de explicação das diferenças.

Estudos constataram, no entanto, que as diferenças de valores pessoais levavam mulheres e homens a definir estratégias diferenciadas para seus negócios ou para seus projetos de negócios, o que, por sua vez, impactava no desempenho de suas empresas ou em suas aspiraçóes empresariais (BOOHENE, SHERIDAN, KOTEY, 2008; ROBICHAUD, ZINGER, LEBRASSEUR,
2007; WILSON, KICKUL, MARLINO, 2007). Kyro (2001) constatou que as mulheres não avaliavam o desempenho de seus negócios por critérios monetários, mas sim associavam o crescimento da firma à autorrealização e à satisfação dos clientes. Machado et al. (2008), ao buscar conhecer o significado de sucesso e fracasso para mulheres empreendedoras, verificaram que essas mulheres já tinham uma ideia formulada daquilo que levava uma empresa a fracassar ou lograr êxito. Pesquisas também associaram o tempo de sobrevivência do negócio e seu desempenho ao capital humano disponível (ARRIBAS, VILA, 2007). A exclusão, senão pelo menos a restrição, da atuação feminina no processo sucessório em organizaçôes familiares foi estudada teoricamente por Machado (2003) e teórica e empiricamente por Macêdo et al. (2004), que verificaram que às mulheres herdeiras, na maioria das vezes, restavam cargos diretivos e gerenciais que eram associados a funçôes consideradas "femininas". Machado, Wetzel e Rodrigues (2008) também analisaram a experiência de sucessão para herdeiras de empresas familiares de diferentes ramos de atividade e constataram a inexistência de um planejamento para ingresso das herdeiras na empresa, a dificuldade e a demora na criação de identidade, a angústia pela ausência de perfil empreendedor, a perda nas redes sociais de contato, o excesso de proteçáo pelo pai e equilíbrio saudável de vida/trabalho. Jonathan (2011), ao analisar a relação das mulheres com o poder, observou que as empreendedoras tendem a construir redes sociais e a exercer o poder com os outros e não sobre os outros. Outro aspecto observado é que, no comando de empreendimentos sociais, as mulheres exercem o poder em prol de mulheres, visando empoderá-las e promover sua inclusão profissional e social. Tal comportamento possibilita mudanças significativas sociais, econômicas e culturais.

O grupo de artigos cujo foco temático foi a representação social e identidade, ora analisou as representaçóes sociais do sujeito feminino construídas pela mídia de negócios nacional e internacional (DIAS et al., 2006), ora investigou se a diferença entre empresários e empresárias estava associada a questóes biológicas ou de 
identidade de gênero (EDDLESTON, POWELL, 2008). Nadim (2007) referiu-se à existência de estereótipos de gênero no meio empresarial que, inclusive, chegava a gerar certo desconforto em empreendedoras, uma vez que a sociedade esperava delas um comportamento de mãe e não de empresária de fato, ainda mais se encontrando à frente de empreendimentos do tipo care. A aceitação desses estereótipos se dava por meio da socialização que tinha origem não só na infância, mas também nas experiências vividas na família, na escola, entre amigos (EDDLESTON, POWELL, 2008; NADIM, 2007; CRAMER et al., 2012). Ferreira e Nogueira (2013) analisaram os elementos que permitem conhecer a subjetividade de mulheres empreendedoras e reconheceram que a subjetividade se dá por meio de uma configuração de sentidos subjetivos advindos tanto do plano individual como também dos construídos socialmente. Verificaram, ainda, que os sentidos subjetivos associados às trajetórias das empreendedoras, ao contexto atual e à cultura na qual a atividade empreendedora é desenvolvida, representam a configuração subjetiva do empreendedorismo para as mulheres. Com isso, identificaram que o empreendedorismo apresenta-se como uma característica individual que inicia a sua constituição na infância e observaram que a experiência das empreendedoras, em ambientes empresariais os quais apresentam condiçóes adversas e mesmo machistas, interfere na constituição da subjetividade feminina. A multiplicidade de papéis e a concorrência entre espaços sociais também atuam na constituição da subjetividade das empreendedoras. Observou-se então que os artigos de Dias et al. (2006), Eddleston e Powell (2008), Nadim (2007), Cramer et al. (2012) e Ferreira e Nogueira (2013) enfatizaram a natureza discursiva da realidade social e da subjetividade.

Os artigos que tratavam das estratégias adotadas por mulheres empreendedoras, de modo geral, argumentaram que o planejamento estratégico era um exercício de aprendizagem e sistematização de ideias e que, sobretudo, auxiliava as empresas no estabelecimento de seus direcionamentos (TAKAHASHI, GRAEFF, TEIXEIRA, 2006). Alguns estudos defenderam que as escolhas estratégicas eram influenciadas tanto por fatores ambientais (NDEMO, MAINA, 2007; GRAY, FINLEY-HERVEY, 2005) quanto por traços e valores pessoais (BOOHENE, SHERIDAN, KOTEY, 2008).

O estudo dos grupos minoritários passou também a despertar o interesse daqueles que pesquisavam o "empreendedorismo feminino", uma vez que muitas mulheres empreendedoras pertencem a minorias étnicas e raciais (PIO, 2007a, 2007b; ROBINSON, BLOCKSON, ROBINSON, 2005). Pio (2007a, 2007b), inclusive, trouxe à tona questôes relacionadas a práticas de exclusão étnica por meio de uma pesquisa qualitativa apurada, desenvolvida ao longo de cinco anos com 45 mulheres indianas que viviam na Nova Zelândia. Tais publicaçôes ora exploraram a experiência e a orientação empreendedora de minorias étnicas e em situação de desvantagem socioeconômica (FULLER-LOVE, LIM, AKEHURST, 2006), ora discutiram a situação de marginalização do mercado formal enfrentada por essa população que, na maioria das vezes, era obrigada a criar um negócio próprio como alternativa de geração de emprego para si e seus familiares (FAIRLIE, 2005). Além disso, esses estudos manifestaram a preocupação sobre a carência de políticas de intervenção institucional que fomentasse e, principalmente, apoiasse esses grupos na implantação e no desenvolvimento de seus negócios (LERNER, MENAHEM, HISRICH, 2005).

Wilson, Kickul e Marlino (2007) argumentaram que as mulheres norte-americanas que se tornavam empresárias enfrentavam muitas dificuldades, principalmente porque não tiveram a oportunidade de aprender e desenvolver as principais habilidades necessárias para se conduzir um negócio. Para eles, a formação e a educação de empresárias se apresentavam como uma alternativa consistente que poderia proporcionar a essas mulheres melhores condições não só de administrar uma empresa como também de torná-la mais competitiva. Tambunan (2007), na Indonésia, e Machado (2001) e Natividade (2009), no Brasil, defenderam a implantação de políticas públicas que viabilizassem a inserção 
da mulher na atividade empreendedora. Assim como Pardo-del-Val e Ribeiro-Soriano (2007), Tambunan (2007) e Winn (2005) sustentaram que a integração da mulher empreendedora em toda a sociedade só se daria por meio da implantação de políticas públicas que disponibilizassem recursos materiais/financeiros e capacitação para aquelas mulheres que tivessem pretensão de se tornarem empresárias. Para Natividade (2009), as políticas públicas nacionais, no período de 2002 a 2007, voltadas para o "empreendedorismo feminino", em especial, para as empreendedoras por necessidade, foram deficientes. A participação dos ministérios na transversalidade de gênero bem como a disponibilidade de recursos orçamentários para políticas efetivas era bastante reduzida, o que denuncia um paradoxo em relação ao crescimento do "empreendedorismo feminino". Tanto Botha, Nieman e Vuuren (2006) quanto Lerner, Menahem e Hisrich (2005) relataram experiências prósperas de programas que se voltaram para a capacitação de mulheres empreendedoras. Os primeiros constataram que as mulheres de um grupo experimental que haviam participado de um Programa de Empreendedorismo Feminino (Women Entrepreneurship Programme - WEP), na África do Sul, ganharam habilidades e conhecimentos novos que contribuíram na condução de seus negócios, ao contrário daquelas que faziam parte do grupo de controle e que não foram atendidas pelo Programa. Os últimos detectaram um impacto positivo de um programa de intervenção do governo que visava ao aperfeiçoamento profissional de imigrantes soviéticas e asiáticas em Israel.

Para alguns autores, as redes contribuem positivamente para a criação e desenvolvimento de novos negócios (VALE, SERAFIM, TEODÓSIO, 2011; GODWIN, STEVENS, BRENNER, 2006; KLYVER, TERJESEN, 2007; WELTER et al., 2004). No entanto, estudos revelaram que a participação feminina em redes ainda é modesta, principalmente na fase inicial do negócio (KLYVER, TERJESEN, 2007), e que, além de elas preferirem resolver seus problemas empresariais utilizando as relaçóes pessoais em vez da assistência das redes (WELTER et al., 2004), suas redes seriam baseadas, na maioria das vezes, na confiança (LOW, 2005). Godwin, Stevens e Brenner (2006) argumentaram que, em contextos dominados por homens, a associaçáo das mulheres a seus pares poderia proporcionar não só o estabelecimento de redes sociais mais fortes e diversas como o acesso a um maior número de recursos e aumento de legitimidade à atividade empreendedora feminina. Vale, Serafim e Teodósio (2011) analisaram e compararam o processo de criação de empresas, implementadas por mulheres e homens, no que diz respeito à imersão em redes sociais. A pesquisa constatou que mulheres e homens encontram-se imersos em redes sociais diferentes, o que condiciona ou influencia a natureza dos empreendimentos que são capazes de construir. Os resultados obtidos apontaram ainda que as mulheres utilizam com maior intensidade laços que lhes são mais próximos para informaçóes e suporte. Os homens, por sua vez, parecem usufruir mais de eventuais benefícios derivados de inserçôes em redes mais amplas e diversificadas, dotadas, inclusive, de mais laços fracos. Dentre os artigos que trataram da temática "redes", Neergaard, Shaw e Carter (2005) não chegaram exatamente a construir uma teoria, mas propuseram um modelo conceitual de rede aplicado a proprietárias de empresas, discutiram suas implicaçôes metodológicas e ainda sugeriram uma agenda de pesquisa.

A relação entre trabalho e família, ou melhor, a busca de conciliação entre eles, também foi um tema investigado pela literatura especializada (STROBINO, TEIXEIRA, 2014; JONATHAN, SILVA, 2007; SHELTON, 2006; SILVA, 2006; LINDO et al., 2004; QUENTAL, WETZEL, 2002; UFUK, ÖZGEN, 2001). Por um lado, algumas pesquisas revelaram que, na visão de muitas mulheres, sair da condição de empregada para se dedicar a uma atividade empresarial gerava mais ganhos do que perdas, principalmente no que dizia respeito à satisfação pessoal, sobretudo porque o autoemprego proporcionava uma flexibilidade de horário que permitia a conciliação entre as atividades domésticas e profissionais (LINDO et al., 2004; QUENTAL, WETZEL, 2002). Por outro lado, estudos detectaram que se a vida econômica era positivamente afetada, 
a vida familiar era atingida negativamente e o nível de estresse dessas mulheres era bem elevado (SILVA, 2006; UFUK, ÖZGEN, 2001). Shelton (2006) constatou que mulheres empreendedoras que viviam esse conflito, em vez da redução ou eliminação de papéis, preferiam a divisão de papéis, pois esta opção permitia que elas otimizassem seu papel tanto no trabalho quanto na família. Jonathan e Silva (2007), ao analisarem a experiência de empresárias, detectaram que elas inovavam incessantemente criando arranjos alternativos para os conflitos que as desafiavam. Strobino e Teixeira (2014), ao analisarem o conflito trabalho-família, estudaram as três dimensôes que podem redundar em conflito entre o trabalho e a família, quais sejam: tempo, tensão e comportamento. Identificaram que o fator tempo é o mais citado como gerador de conflitos e o controle emocional é a ação mais citada como atenuante desses conflitos. Schindehutte, Morris e Brennan (2001) examinaram o impacto do empreendedorismo sobre as experiências, percepções e planos futuros dos filhos de empresárias. Ao pesquisarem amostras nos Estados Unidos e na África do Sul, constataram que, apesar de a vida familiar ser invadida pelas demandas da empresa, o fato de as crianças crescerem ao lado de máes empreendedoras trouxe experiências positivas e, inclusive, influenciou essas crianças a buscarem experiências empreendedoras mais tarde.

A revisão de literatura a respeito dos trabalhos que investigaram o "empreendedorismo feminino" pós anos 1990 revelou que as metodologias adotadas foram as mais variadas possíveis, não obstante o predomínio daquelas de caráter quantitativo. Muitos adotaram principalmente as pesquisas internacionais e o método survey e desenvolveram estudos transversais e/ou longitudinais usando questionários ou entrevistas estruturadas para a coleta de dados. Em alguns casos, os surveys utilizaram amostras de empreendedoras de diferentes países, compararam os resultados e realizaram generalizaçôes. Em outros casos, as amostras foram de empreendedoras e/ou empreendedores ora na condição de estudantes ora de profissionais liberais que trabalhavam por conta própria. Alguns pesquisadores chegaram até a realizar os denominados e-mail-surveys, aplicando o questionário junto à população-alvo através do correio eletrônico. Dentro dessa categoria, McClelland et al. (2005), ao investigarem as principais características de empreendedoras em seis países, adotaram a metodologia internet-based, ou seja, coletaram os dados empíricos através de portais institucionais, sites de relacionamento e correios eletrônicos. Os dados coletados junto às mulheres empreendedoras permitiram que os pesquisadores concluíssem que as experiências são diferentes entre os países e dentro deles. Ainda houve surveys que combinaram estratégias de pesquisa, como o grupo focal e entrevista por telefone, para enriquecer suas análises.

Entre os trabalhos de natureza qualitativa, houve uma predominância de estudos de caso que utilizaram entrevistas semiestruturadas ou em profundidade como técnica. A pesquisa de Dechant e Lamky (2005) é um exemplo de estudo de caso que adotou entrevistas em profundidade. As pesquisadoras apresentaram a experiência de dez mulheres árabes na região de Bahrain e Oman, no Golfo da Arábia, que iniciaram seu próprio negócio, concluindo que, não obstante a influência do ambiente cultural, a experiência dessas mulheres geralmente assemelhava-se à de outras mulheres de outras partes do mundo. Um exemplo bem-sucedido de estudo de caso que adotou a entrevista em profundidade foi o de Pio (2007a; 2007b), que entrevistou 45 indianas ao longo de cinco anos na Nova Zelândia.

Entre os artigos de natureza qualitativa, a análise do discurso também foi adotada, tanto em nível nacional quanto internacional. No presente estudo, detectou-se que a análise do discurso teve como objeto publicaçóes em revistas, como foi o caso da pesquisa desenvolvida por Dias et al. (2006) que exploraram os meandros da construção de uma imagem social forjada através de um discurso mais sedutor do que crítico de uma revista de alta circulação nacional. A análise do discurso também foi aplicada a partir do depoimento oral de entrevistadas, como na pesquisa de Nadin (2007), que explorou a forma como duas empresárias do care sector lutavam para estabelecer uma identidade positiva ao conciliar as 
posiçóes contraditórias produzidas na intersecção entre as demandas do contexto empresarial e as demandas do care sector. Por seu turno, Cramer et al. (2012) utilizaram a análise do discurso com vistas a compreender as percepçóes de empreendedoras sobre o mundo dos negócios. $\mathrm{O}$ estudo revelou que o gênero tem uma origem contextual/ situacional e histórica e precisa ser compreendido desta forma por se constituir em práticas discursivas socialmente construídas.

\section{CONSIDERAÇÓES FINAIS}

Não obstante a contribuição de cada estudo, pois, no conjunto, forneceram dados e informaçôes relevantes a respeito da mulher empreendedora, muitas pesquisas se limitaram a descrever, de forma fragmentada, pequenos segmentos da população de mulheres empreendedoras e não avançaram na aplicação e no desenvolvimento de teorias. Aliás, essa foi também a percepção de Moore (1990), quando analisou a literatura que havia sido produzida em anos anteriores sobre mulheres empreendedoras.

Ademais, na maioria das vezes, os estudos foram de natureza quantitativa e empírica e prenderam-se à tentativa de traçar um "perfil" da mulher empreendedora. Essa tentativa gerou muitos estudos que buscaram apontar diferenças entre homens e mulheres por meio de dados demográficos, familiares, ocupacionais e educacionais. Por um lado, esses dados contribuíram bastante para o conhecimento a respeito da mulher empreendedora. Por outro, reforçaram o estereótipo de que as mulheres possuíam uma "essência" que determinava habilidades e atributos. Em outras palavras, parece que um processo artificial de naturalização levou a crer que o empreendedor ou a empreendedora são pessoas dotadas de características "naturalmente" determinadas. Aliás, parece que boa parte das pesquisas não se deu conta de que concepçóes essencialistas têm norteado a produção acadêmica sobre "empreendedorismo feminino". A estruturaçáo extremamente persuasiva desse discurso consegue se impregnar com tanta profundidade nas sociedades que náo surpreende o fato de a literatura que trata do "empreendedorismo feminino" náo ter ficado ilesa a ele.

Poucos foram os estudos que elaboraram uma análise teórica especificamente sobre a temática "gênero". Ao que parece, a preocupação recorrente de muitos trabalhos esteve centrada na estrutura sexuada das organizaçóes e em suas consequências para as atividades empresariais. Com isso, parece ser oportuno trazer para o debate a discussão a respeito da necessidade de se adotar novas lentes para se estudar o fenômeno do "empreendedorismo feminino", senão pelo menos de se estabelecer novos rumos a sua pesquisa.

A necessidade de que pesquisas adicionais fossem desenvolvidas para se chegar a qualquer tipo de conclusão a respeito de um pretenso estabelecimento de um "perfil empreendedor" das mulheres foi sentida por vários pesquisadores. Ahl (2006), por exemplo, ao constatar que, apesar de intençôes contrárias, a produção acadêmica que trata do "empreendedorismo feminino" possuía determinadas práticas discursivas que reproduziam a subordinação feminina, ou seja, que recriava a ideia de que as empresas geridas por mulheres desempenhavam um papel secundário e menos significativo quando comparadas àquelas lideradas por homens, sugeriu que as pesquisas futuras sobre o tema ampliassem seu objeto de pesquisa e mudassem sua posição epistemológica. A pesquisa de Ahl (2006) reforçou a percepção inicial de que parece faltar diversidade epistemológica na produção científica que trata do "empreendedorismo feminino", de mulheres empreendedoras, de mulheres proprietárias de empresas etc., uma vez que parte substancial dos estudos parece entender sexo/gênero como uma variável e não como um quadro de referência.

Náo obstante o predomínio de estudos de orientação normativa, notou-se que tem crescido o número de pesquisas que concebe o gênero como construção social asseguradora da subordinação das mulheres aos homens e, sobretudo, que compreende que sexo e gênero são práticas discursivas que constituem subjetividades específicas por meio de poder e resistência na materialidade dos corpos humanos. Eles, sobretudo, não só propõem a desconstrução e a desnaturalização das práticas discursivas consideradas universais como também 
dão voz a minorias étnicas, que não são tratadas no mainstream, e problematizam o conceito de gênero como constituído no Ocidente.

O balanço aqui realizado buscou espelhar a produção acadêmica nacional e internacional sobre "empreendedorismo feminino", principalmente nos periódicos e anais de eventos da área de administração. Demonstra o nascimento de um campo de pesquisa, sua transformaçáo e seu amadurecimento pari passu às mudanças na sociedade, no mercado de trabalho e na academia. Apesar dos avanços, ainda se tem uma longa trajetória a construir.

\section{REFERÊNCIAS}

AHL, H. Why research on women entrepreneurs needs new directions? Entrepreneurship Theory and Practice, [S. 1.], v. 30, n.5, p. 595-621, Sept. 2006.

ALDRICH, H.; REESE, P. R.; DUBINI, P. Women on the verge of a breakthrough?: networking among entrepreneurs in the United States and Italy. In: VESPER, K. H. (Ed.) Frontiers of entrepreneurship research. Wellesley, Massachusetts: Babson College, p. 560-574, 1989.

ALLEN, K. R.; CARTER, N. M. Women entrepreneurs: profile differences across high and low performing adolescent firms. Frontiers of Entrepreneurship Research, 1996.

ALSOS, G. A.; ISAKSEN, E. J.; LJUNGGREN, E. New venture financing and subsequent business growth in men-and women-led businesses. Entrepreneurship Theory and Practice, [S. 1.], v. 30, n. 5, p. 667-686, Sept. 2006.

ARRIBAS, I.; VILA, J. E. Human capital determinants of the survival of entrepreneurial service firms in Spain. The International Entrepreneurship and Management Journal, [S.1.], v. 3, n. 3, p. Sept. 2007.

BECKER-BLEASE, J. R.; SOHL, J. E. Do women-owned businesses have equal access to angel capital? Journal of Business Venturing, Amsterdam, v. 22, n. 4, p. 503-521, July 2007.

BIERNACKI, P., WALDORF, D. Snowball sampling: problems and techniques of chain referral sampling. Sociological Methods \& Research, [S. 1.], v. 2, n. 2, p.141-163, Nov. 1981.

BOOHENE, R.; SHERIDAN, A.; KOTEY, B. Gender, personal values, strategies and small business performance. Equal Opportunities International, [S. 1.], v. 27, n. 3, p. 237-257, 2008.

BJÖRNSSON, B.; ABRAHA, D. Counselling encounters between banks and entrepreneurs: a gender perspective. International Journal of Bank Marketing, Bradford, v. 23, n. 6, p. 444463, 2005.

BOOHENE, R.; SHERIDAN, A.; KOTEY, B. Gender, personal values, strategies and small business performance. Equal Opportunities International, [S. 1.], v. 27, n. 3, p. 237-257, 2008.

BOTHA, M.; NIEMAN, G.; VUUREN, J. Enhancing female entrepreneurship by enabling access to skills. Entrepreneurship Management, [S. 1.], v. 2, n. 4, p. 479-493, Dec. 2006.

BRUIN, A.; FLINT-HARTLE, S. Entrepreneurial women and private capital: the New Zealand perspective. International Journal of Entrepreneurial Behaviour \& Research, [S. 1.], v. 11, n. 2, p. 108-128, 2005.

BUTTNER, E. H.; ROSEN, B. Bank loan officers' perceptions of the characteristics of men, women, and successful entrepreneurs. Journal of Business Venturing, Amsterdam, v. 3, n. 3, p. 249-258, Summer 1988.

CANTZLER, I.; LEIJON, S. Team-oriented women entrepreneurs: a way to modern management. Journal of Small Business and Enterprise Development, Bradford, v. 14, n. 4, p. 732-746, 2007.

CARTER, N. M. The role of risk orientation on financing expectations in new venture creation: 
does sex matter? Frontiers of Entrepreneurship Research, 2002. Disponível em: <www.babson. edu>. Acesso em: 05 fev. 2012.

CARTER, S. The dynamics and performance of female-owned entrepreneurial firms. Journal of Organizational Change Management. Bradford, v. 2, n. 3, p. 54-64, 1989.

; et al. Gender, entrepreneurship, and bank lending: the criteria and processes used by bank loan officers in assessing applications. Entrepreneurship Theory and Practice, [S. 1.], v. 31, n. 3, p. 427-444, May 2007.

CASSOL, N. K.; SILVEIRA, A.; HOELTGEBAUM, M. Empreendedorismo feminino: análise da produção científica da base de dados do Institute for Scientific Information (ISI), 1997-2006. In: ENCONTRO NACIONAL DA ASSOCIAÇÃO DOS PROGRAMAS DE PÓS-GRADUAÇÃO EM ADMINISTRAÇÃO, 31., 2007. Salvador. Anais... Salvador: ANPAD, 2007. 1 CD-ROM.

CHEW, I. K. H.; YAN, T. C. The changing pattern of women entrepreneurs: the Singapore experience. Women in Management Review, Bradford, v. 6, n. 6, 1991.

COLEMAN, S. Access to capital: a comparison of men and women. Frontiers of Entrepreneurship Research, 1998. Disponível em: < http://www. babson.edu/entrep /fer/papers98/V/V_B/V_B. html>. Acesso em: 24 out. 2007.

COOK, R. G.; BELliVEAU, P.; LENTZ, C. The role of gender in US microenterprise business plan development. Journal of Small Business and Enterprise Development, Bradford, v. 14, n. 2, p. 241-251, 2007.

CRAMER, L. et al. Representações femininas da ação empreendedora: uma análise da trajetória das mulheres no mundo dos negócios. Revista de Empreendedorismo e Gestáo de Pequenas Empresas, São Paulo, v.1, n.1, 53-71, jan./abril, 2012.
CROMIE, S.; BIRLEY, S. Networking by female business owners in Northern Ireland. Journal of Business Venturing, Amsterdam, v. 7, n. 3, p. 237-251, May 1992.

DECARLO, J. F; LYONS, P. R. A comparison of selected personal characteristics of minority and non-minority female entrepreneurs. Journal of Small Business Management, Morgantown, v. 17, n. 4 , p. 222-229, Oct. 1979.

DECHANT, K.; LAMKY, A. Toward an understanding of arab women entrepreneurs in Bahrain and Oman. Journal of Developmental Entrepreneurship, Norfolk, v. 10, n. 2, p. 123-140, Ago. 2005.

DE TIENNE, D. R.; CHANDLER, G. N. The role of gender in opportunity identification. Entrepreneurship Theory and Practice, [S. 1.], v. 31, n. 3, p. 365-386, May 2007.

DHALIWAL, S.; KANGIS, P. Asians in the UK: gender, generations and enterprise. Equal Opportunities International, Bradford, v. 25, n. 2, p. 92-108, 2006.

DIAS, V. T. et al. A idealização da profissional adequada aos "novos tempos". In: ENCONTRO NACIONAL DA ASSOCIAÇÃO DOS PROGRAMAS DE PÓS-GRADUAÇÃO EM ADMINISTRAÇÃO, 30., 2006. Salvador. Anais... Salvador: ANPAD, 2006. 1 CD-ROM.

DIEGUES-CASTRILLON, M. I. et al. Turismo rural, empreendedorismo e gênero: um estudo do caso na comunidade autônoma da Galiza. Revista de Sociologia e Economia Rural, Brasília, v. 50, n. 2, p. 371-382, abr./jun, 2012.

DOLINSKY, A. L.; CAPUTO, R. K.; PASUMARTY, K. Long-term entrepreneurship patterns: a national study of black and white female entry and stayer status differences. Journal of Small Business Management. Morgantown, v. 32, n. 1, p. 18-26, Jan. 1994.

EDDLESTON, K. A.; POWELL, G. N. The role of gender identity in explaining sex differences 
in business owners' career satisfier preferences. Journal of Business Venturing, Amsterdam, v. 23, n. 2, p. 244-256, Mar. 2008.

FAGENSON, E. A. Personal value systems of men and women entrepreneurs versus managers. Journal of Business Venturing, v. 8, n. 5, p. 409-430, Sept. 1993.

FAIRLIE, R. W. Entrepreneurship and earnings among young adults from disadvantaged families.

Small Business Economics, Dordrecht, v. 25, n. 3, p. 223-236, Oct. 2005.

FASCI, M. A.; VALDEZ, J. A performance contrast of male- and female-owned small accounting practices. Journal of Small Business Management, Morgantown, v. 36, n. 3, p. 1-7, July 1998.

FERREIRA, J. M.; GIMENEZ, F. A. P.; RAMOS, S. C. Potencial empreendedor e gênero: estudo com varejistas de materiais de Curitiba/ PR. In: ENCONTRO DE ESTUDOS SOBRE EMPREENDEDORISMO E GESTÃO DE PEQUENAS EMPRESAS, 4., 2005. Curitiba. Anais... Curitiba: UEL/UEM/PUC-PR/PPA, 2005. 1 CD-ROM.

; NOGUEIRA, E. E. S. Mulheres e suas histórias: razão, sensibilidade e subjetividade no empreendedorismo feminino. Revista de Administraçáo Contemporânea, Curitiba, v. 17, n. 4, p. 398-417, jul./ago. 2013.

FISCHER, E. M.; REUBER, A. R.; DYKE, L. S. A theoretical overview and extension of research on sex, gender, and entrepreneurship. Journal of Business Venturing, New York, v. 8, n. 2, p. 151-168, Mar. 1993.

FULLER-LOVE, N.; LIM, L.; AKEHURST, G. Guest editorial: female and ethnic minority entrepreneurship. The International Entrepreneurship Management Journal, [S. 1.], v. 2, n. 4, p. 429-439, Dec. 2006.

GATEWOOD, E. J. et al. Toward a theory of women entrepreneurship and venture capital.
Frontiers of Entrepreneurship Research, 2003. Disponível em: <http://www.babson.edu/entrep/ fer/BABSON2003>. Acesso em: 24 out. 2007.

GIMENEZ, F. A. P. et al. Gênero e Empreendedorismo: um estudo comparativo no Paraná. In: ENCONTRO DE ESTUDOS SOBRE EMPREENDEDORISMO E GESTÃO DE PEQUENAS EMPRESAS, 1., 2000. Anais... Maringá: UEL/UEM/PPA, 2000. 1 CD-ROM.

GLOBAL ENTERPRENEURSHIP MONITOR (GEM) 2013a. Empreendedorismo no Brasil: relatório executivo 2013. Disponível: < http://ibqp.org.br/upload/tiny_mce/Download/ GEM_2013_-_Relatorio_executivo_Empreendedorismo_no_Brasil.pdf>.Acesso: 06 jun. 2014.

GLOBAL ENTREPRENEURSHIP MONITOR (GEM) 2013b. Empreendedorismo no Brasil 2013. Curitiba: IBQP, 2013. Disponível em: < http://www.ibqp.org.br/upload/tiny_mce/ GEM_2013_-_Livro_Empreendedorismo_no_ Brasil.pdf>. Acesso: 06 jun. 2014.

GODWIN, L. N.; STEVENS, C. E.; BRENNER, N. L. Forced to play by the rules? Theorizing how mixed-sex founding teams benefit women entrepreneurs in male-dominated contexts. Entrepreneurship Theory and Practice, [S. 1.], v. 30, n. 5, p. 623-642, Sept. 2006.

GRAY, K. R.; FINLEY-HERVEY, J. Women and entrepreneurship in Morocco. The International Entrepreneurship and Management Journal, [S. 1.], v. 1, n. 2, p. 203-217, 2005.

HARRISON, R. T.; MASON, C. M. Does gender matter? Women business angles and the supply of entrepreneurial finance. Entrepreneurship Theory and Practice, [S. 1.], v. 31, n. 5, p. 445-472, May 2007.

HISRICH, R. D. et al. Performance in entrepreneurial ventures: does gender matter?. Frontiers of Entrepreneurship Research, 1997. Disponível em: < http://www.babson.edu/ entrep/fer/papers97/sum97/hisb.htm>. Acesso em 23 out. 2007. 
; BRUSH, C. The woman entrepreneur: management skills and business problems. Journal of Small Business Management, Morgantown, v. 22, n. 3, p. 30-37, Jan. 1984.

; BRUSH, C. G. Women entrepreneurs: a longitudinal study. In: VESPER, K. H. (Ed.). Frontiers of entrepreneurship Research. Wellesley, Massachusetts: Babson College, p. 187-199, 1987.

; FAN, Z. Women entrepreneurs in the people's Republic of China: an exploratory study. Journal of Managerial Psychology, Bradford, v. 6, n. 3, p. 3-12, 1991.

; O`BRIEN, M. The woman entrepreneur from a business and sociological perspective. In: VESPER, K. H. (Ed.) Frontiers of Entrepreneurship Research. Wellesley, Massachusetts: Babson College, p. 21-39, 1981.

HOLMQUIST, C.; SUNDIN, E. Women as entrepreneurs in Sweden: conclusions from a survey. In: VESPER, K. H. (Ed.) Frontiers of Entrepreneurship Research. Wellesley, Massachusetts: Babson College, p. 626-642, 1989.

JONATHAN, E. G. Empreendedorismo feminino no setor tecnológico brasileiro: dificuldades e tendências. In: ENCONTRO DE ESTUDOS SOBRE EMPREENDEDORISMO E GESTÃO DE PEQUENAS EMPRESAS, 3., 2003. Brasília. Anais... Brasília: UEL/UEM/PPA/UnB, 2003. 1 CD-ROM.

Mulheres empreendedoras: o desafio da escolha do empreendedorismo e o exercício do poder. Psicologia Clínica, Rio de Janeiro, v. 23, n. 1, p. 65-85, 2011.

Mulheres empreendedoras: medos, conquistas e qualidade de vida. Psicologia em Estudo, Maringá, v. 10, n. 3, p. 373-382, set./ dez. 2005.

; SILVA, T. M. R. Empreendedorismo feminino: tecendo a trama de demandas conflitantes. Psicologia \& Sociedade, Belo Horizonte, v. 19, n. 1, p. 77-84, jan./abr. 2007.
JOOS, M. Women: the entrepreneurs of the 1980s. Reference Services Review, Bradford, v. 15, n. 3, p. 59-65, 1987.

KEPHART, P.; SCHUMACHER, L. Has the 'glass ceiling' cracked?: an exploration of women entrepreneurship. Journal of Leadership \& Organizational Studies, [S. 1.], v. 12, n. 1, p. 2-15, Fall 2005.

KIRKWOOD, J. Igniting the entrepreneurial spirit: is the role parents play gendered? International Journal of Entrepreneurial Behaviour \& Research, [S. 1.], v. 13, n. 1, p. 39-59, 2007.

KLYVER, K.; TERJESEN, S. Entrepreneurial network composition. Women in Management Review, Bradford, v. 22, n. 8, p. 682-688, 2007.

KYRO, P. Women entrepreneurs question men's criteria for success. Frontiers of Entrepreneurship Research, 2001. Disponível em: <http:// fusionmx.babson.edu/entrep/fer/babson2001/ IV/IVC/IVC.htm >. Acesso em: 23 out. 2007.

LEAHY, K. T.; EGGERS, J. H. Is gender still a factor in entrepreneurial leader behavior? Frontiers of Entrepreneurship Research, 1998. Disponível em: <http://www.babson.edu/entrep/ fer/papers98/V/V_F/V_F_text.htm >. Acesso em: 23 out. 2007.

LEE-GOSSELIN, H.; GRISÉ J. Are women owner-managers challenging our definitions of entrepreneurship? An in-depth survey. Journal of Business Ethics, Dordrecht, v. 9, n. 4-5, p. 423-433, Apr./May 1990.

LERNER, M.; MENAHEM, G.; HISRICH, R. D. Does government matter? The impact of occupational retraining, gender and ethnicity on immigrants' incorporation. Journal of Small Business and Enterprise Development, Bradford, v. 12, n. 2, p. 192-210, 2005.

LIMA, R. C. R.; FREITAS, A. A. F. Personalidade empreendedora, recursos pessoais, ambiente, atividades organizacionais, gênero e desempenho financeiro de empreendedores informais. Revista 
de Administração Pública, Rio de Janeiro, v. 44, n. 2, p. 511-531, mar./abr. 2010.

LINDO, M. R. et al. Conflito vida pessoal $v s$. vida profissional: os desafios de equilíbrio para mulheres empreendedoras do Rio de Janeiro. In: ENCONTRO NACIONAL DA ASSOCIAÇÃO DOS PROGRAMAS DE PÓS-GRADUAÇÃO EM ADMINISTRAÇÃO, 28., 2004. Curitiba. Anais... Curitiba: ANPAD, 2004. 1 CD-ROM.

LOW, A. A matter of trust: how a group of female immigrant entrepreneurs build overseas business network. Frontiers of Entrepreneurship Research, 2005. Disponível em: <http://www.babson.edu >. Acesso em: 27 out. 2007.

MACÊDO, K. B. et al. O processo sucessório em organizaçôes familiares e a exclusão da mulher. Psicologia \& Sociedade, Porto Alegre, v. 16, n. 3, p. 69-81, set./dez. 2004.

MACHADO, H. P. V. Empreendedorismo, gênero e políticas públicas. In: ENCONTRO DE ESTUDOS SOBRE EMPREENDEDORISMO E GESTÃO DE PEQUENAS EMPRESAS, 2., 2001. Londrina. Anais... Londrina: UEL/UEM/ PPA, 2001. 1 CD-ROM.

Sucessão familiar e gênero: implicações para estudos sobre empresas familiares. In: ENCONTRO DE ESTUDOS SOBRE EMPREENDEDORISMO E GESTÃO DE PEQUENAS EMPRESAS, 3., 2003. Brasília. Anais... Brasília: UEL/UEM/PPA/UnB, 2003. 1 CD-ROM.

Tendências do comportamento gerencial da mulher empreendedora. In: ENCONTRO NACIONAL DA ASSOCIAÇĀO DOS PROGRAMAS DE PÓS-GRADUAÇÃO EM ADMINISTRAÇÃO, 23., 1999. Maringá. Anais... Maringá: ANPAD, 1999. 1 CD-ROM.

; JANEIRO, V.; MARTINS, A. B. T. Empreendedoras: estilo gerencial e desempenho das empresas. In: ENCONTRO NACIONAL DA ASSOCIAÇĀO DOS PROGRAMAS DE PÓS-GRADUAÇÃO EM ADMINISTRAÇÃO,
27., 2003. Atibaia. Anais... Atibaia: ANPAD, 2003. 1 CD-ROM.

; et al. O processo de criação de empresas por mulheres. RAE-eletrônica, São Paulo, v. 2, n. 2, jul./dez. 2003. Disponível em: <http://www. scielo.br/pdf/raeel/v2n2/v2n2a07>. Acesso em: 23 out. 2007.

; et al. Significados de sucesso e fracasso nos negócios: o que dizem mulheres empreendedoras. In: ENCONTRO NACIONAL DA ASSOCIAÇÃO DOS PROGRAMAS DE PÓS-GRADUAÇÃO EM ADMINISTRAÇÃO, 32., 2008. Rio de Janeiro. Anais... Rio de Janeiro: ANPAD, 2008. 1 CD-ROM.

MACHADO, R. M. C.; WETZEL, U.; RODRIGUES, M. E. A experiência de sucessão para herdeiras de empresas familiares do Rio de Janeiro. Cadernos EBAPE, Rio de Janeiro, v. 6, n. 3, p. 1-24, set. 2008 .

MANOLOVA, T. S. et al. The differential effect of men and women entrepreneurs' human capital and networking on growth expectancies in Bulgaria. Entrepreneurship Theory and Practice, [S. 1.], v. 31, n. 3, p. 407-426, May 2007.

MARLOW, S.; PATTON, D. All credit to men? Entrepreneurship, finance, and gender. Entrepreneurship Theory and Practice, [S. 1.], v. 29, n. 6, p. 717-735, Nov. 2005.

MCCLELLAND, E. et al. Following the pathway of female entrepreneurs. International Journal of Entrepreneurial Behaviour \& Research, [S. 1.], v. 11, n. 2, p. 84-107, 2005.

MENZIES, T. V. et al. A longitudinal study of the characteristics, business creation process and outcome differences of Canadian female vs. male nascent entrepreneurs. Entrepreneurship Management, [S. 1.], v. 2, n. 4, p. 441-453, Dec. 2006.

MOORE, D. P. An examination of present research on the female entrepreneur - suggested research strategies for the 1990's. Journal of Business Ethics, v. 9, n. 4-5, p. 275-281, Apr./May 1990. 
NADIN, S. Entrepreneurial identity in the care sector: navigating the contradictions. Women in Management Review, Bradford, v. 27, n. 6, p. 456-467, 2007.

NATIVIDADE, D. R. Empreendedorismo feminino no Brasil: políticas públicas sob análise. Revista de Administraçáo Pública, Rio de Janeiro, v. 43, n. 1, p. 231-256, jan./fev. 2009.

NDEMO, B.; MAINA, F. W. Women entrepreneurs and strategic decision making. Management Decision, Bradford, v. 45, n. 1, p. 118-130, 2007.

NEERGAARD, H.; SHAW, E.; CARTER, S. The impact of gender, social capital and networks on business ownership: a research agenda. International Journal of Entrepreneurial Behaviour \& Research, [S. 1.], v. 11, n. 5, p. 338-357, 2005.

NEIDER, L. A preliminary investigation of female entrepreneurs in Florida. Journal of Small Business Management, Morgantown, v. 25, n. 3, p. 22-29, 1987.

ORSER, B. J.; RIDING, A.; MADILL, J. J. The value of gender-based small business programs: what does the evidence say? Frontiers of Entrepreneurship Research, 2002. Disponível em: <http://www.babson.edu >. Acesso em: 27 out. 2007.

; RIDING, A. L.; MANLEY, K. Women entrepreneurs and financial capital. Entrepreneurship Theory and Practice, [S. 1.], v. 30, n. 5, p. 643-665, Sept. 2006.

PARDO-DEL-VAL, M.; RIBEIRO-SORIANO, D. Political support for women entrepreneurs: the EQUAL community initiative in Spain and Portugal. Equal Opportunities International, Bradford, v. 26, n. 8, p. 761-777, 2007.

PELISSON, C. et al. Comportamento gerencial, gênero e empreendedorismo. In: ENCONTRO NACIONAL DA ASSOCIAÇÃO DOS PROGRAMAS DE PÓS-GRADUAÇĀO EM
ADMINISTRAÇÃO, 25., 2001. Campinas. Anais... Campinas: ANPAD, 2001. 1 CD-ROM.

PIO, E. Ethnic entrepreneurship among indian women in New Zealand: a bittersweet process. Gender, Work and Organization, Oxford, v. 14, n. 5, Sept. 2007a.

Ethnic minority migrant women entrepreneurs and the imperial imprimatur. Women in Management Review, Bradford, v. 22, n. 8, p. 631-649, 2007b.

QUENTAL, C.; WETZEL, U. Equilíbrio trabalho-vida e empreendedorismo: a experiência das mulheres brasileiras. In: ENCONTRO NACIONAL DA ASSOCIAÇÃO DOS PROGRAMAS DE PÓS-GRADUAÇÃO EM ADMINISTRAÇÃO, 26., 2002. Salvador. Anais... Salvador: ANPAD, 2002. 1 CD-ROM.

RENTSCHLER,R. Painting equality: female artists as cultural entrepreneurial marketers. Equal Opportunities International, Bradford, v. 26, n. 7, p. 665-677, 2007.

ROBICHAUD, Y.; ZINGER, J. T.; LEBRASSEUR, R. Gender differences within early stage and established small enterprises: an exploratory study. International Entrepreneurship Management Journal, [S. 1.], v. 3, n. 3, p. 323-343, Sept. 2007.

ROBINSON, J.; BLOCKSON, L.; ROBINSON, S. African american women entrepreneurs and firm growth. Frontiers of Entrepreneurship Research, 2005. Disponível em: <http://www. babson.edu>. Acesso em: 27 out. 2007.

RODRIGUES, M. E.; WETZEL, U. As motivaçôes das empreendedoras de serviços de bufês do Estado do Rio de Janeiro na decisão de iniciar o seu negócio. In: ENCONTRO NACIONAL DA ASSOCIAÇÃO DOS PROGRAMAS DE PÓS-GRADUAÇÃO EM ADMINISTRAÇÃO, 27., 2003. Atibaia. Anais... Atibaia: ANPAD, 2003. 1 CD-ROM. 
RODRÍGUEZ, M. J.; SANTOS, F. J. Women nascent entrepreneurs and social capital in the process of firm creation. International Entrepreneurship Management Journal, [S. 1.], v. 5, n. 1, p. 45-64, Mar. 2009.

SCHINDEHUTTE, M.; MORRIS, M.; BRENNAN, C. Female entrepreneurs and their children: implications for family life, career aspirations and entrepreneurial perceptions. Frontiers of Entrepreneurship Research, 2001. Disponível em: <http://www.babson.edu/entrep/ fer/Babson2001/IV/IVF/IVF.htm>. Acesso em: 24 out. 2007.

SCHWARTZ, E. B. Entrepreneurship: a new female frontier. Journal of Contemporary Business, Seattle, v. 5, n. 1, p. 47-76, 1976.

SERNA, M. G. La actividad empresarial feminina em México: lãs últimas 3 décadas. Revista El Mercado de Valores, v. 62, n.1, p. 3-12, enero 2002.

SEXTON, D. L.; BOWMAN-UPTON, N. Female and male entrepreneurs: psychological characteristics and their role in gender-related discrimination. Journal of Business Venturing, Amsterdam, v. 5, n. 1, p. 29-36, Jan. 1990.

SEXTON, D. L.; KENT, C., A. Female executives and entrepreneurs: a preliminary comparison. In: VESPER, K. H. (Ed.). Frontiers of entrepreneurship Research. Wellesley, Massachusetts: Babson College, p. 40-55, 1981.

SHELTON, L. M. Female entrepreneurs, workfamily conflict, and venture performance. Journal of Small Business Management, Morgantown, v. 44, n. 2, p. 285-297, 2006.

SILVA, J. V. A. A relação trabalho e família de mulheres empreendedoras. Revista Perspectiva Contemporânea, Campo Mourão, v. 1, n. 1, p. 1-18, jan./jul. 2006.

SINGH, G.; BELWAL, R. Entrepreneurship and SMEs in Ethiopia. Gender in Management: An International Journal, Bradford, v. 23, n. 2, p. 120-136, 2008.
SMITH, N. R.; MCCAIN, G.; WARREN, A. Women entrepreneurs really are different: a comparison of constructed ideal of male and female entrepreneurs. In: VESPER, K. H. (Ed.). Frontiers of entrepreneurship Research. Wellesley, Massachusetts: Babson College, p. 68-76, 1982.

STEVENSON, L. Some methodological proble$\mathrm{ms}$ associated with researching women entrepreneurs. Journal of Business Ethics, Dordrecht, v. 9, n. 4-5, p. 439-446, Apr./May 1990.

STEVENSON, L. A. Against all odds: the entrepreneurship of women. Journal of Small Business Management, Milwaukee, v. 24, n. 4, p. 30-36, Oct. 1986.

STILL, L. V.; WALKER, E. A. The self-employed woman owner and her business: an Australian profile. Women in Management Review, Bradford, v. 21, n. 4, p. 294-310, 2006.

STROBINO, M. R. C.; TEIXEIRA, R. M. Empreendedorismo feminino e o conflito trabalho-família: estudo de multicasos no setor de comércio de material de construção da cidade de Curitiba. Revista de Administraçáo, São Paulo, v. 49, n.1, p.59-76, jan./fev./mar. 2014.

TAKAHASHI, A. R. W.; GRAEFF, J. F. Empreendedorismo, gestão feminina e planejamento estratégico em Mpe. In: SEMINÁRIOS EM ADMINISTRAÇÃO, 8., 2005. São Paulo. Anais... São Paulo: FEA-USP, 2005.1 CD-ROM.

; TEIXEIRA, R. M. Planejamento estratégico e gestão feminina em pequenas empresas. Organizaçáo \& Sociedade, [S. 1.], v. 13, n. 39, 2006.

TAMBUNAN, T. Entrepreneurship development: SMES in Indonesia. Journal of Developmental Entrepreneurship, Norfolk, v. 12, n. 1, p. 95-118, 2007.

TERJESEN, S. Senior women managers'transition to entrepreneurship: leveraging embedded career capital. Career Development International, v. 10, n. 3, p. 246-259, 2005. 
UFUK, H.; ÖZGEN, Ö. Interaction between the business and family lives of women entrepreneurs in Turkey. Journal of Business Ethics, Dordrecht, 31, n. 2, p. 95-106, May 2001.

VALE, G. M. V.; SERAFIM, A. C. F; TEODÓSIO, A. S. S. Gênero, imersão e empreendedorismo: sexo frágil, laços fortes? Revista de Administração Contemporânea, Curitiba, v. 15, n. 4, p. 631-649, jul./ago. 2011.

VERHEUL, I. Commitment or control? Human resource management practices in female- and male-led businesses. 2003. ERIM report series research in management. Disponível em: <http:// www. spea.indiana.edu/ids/bridge/2003Papers/ ZMon_Verheul.pdf>. Acesso em: 27 out. 2007.

VERHEUL, I.; THURIK, A. R. Explaining the entrepreneurial activity rate of women: a macro-economic view. Frontiers of Entrepreneurship Research, 2003.

WAGNER, J. What a difference a y makes: female and male nascent entrepreneurs in Germany. Small Business Economics, Dordrecht, v. 28, n. 1, p. 1-21, 2007.

WALKER, E. A.; WEBSTER, B. J. Gender, age and self-employment: some things change, some stay the same. Women in Management Review, Bradford, v. 22, n. 2, p. 122-135, 2007.

WALKER, E.; WEBSTER, B. Management competencies of women business owners. Entrepreneurship Management, [S. 1.], v. 2, n. 4, p. 495-508, Dec. 2006.

WALSH, D.; DOWNE, S. J. Meta-synthesis method for qualitative research: a literature review. Journal of Advanced Nursing. Oxford, v. 50, n.2, p. 204-211, 2005.

WATKINS, J.; WATKINS, D. S. The female entrepreneur: her background and determinants of business choice - some British data. In: VESPER, K. H. (Ed.) Frontiers of Entrepreneurship Research. Wellesley, Massachusetts: Babson College, p. 271-288, 1983.
WATSON, J. Revisiting the female under-performance hypothesis. Frontiers of Entrepreneurship Research, 2002. Disponível em: < http:// www.babson.edu/entrep/fer/ BABSON2002/VI/ VI_S6/VI_S6.htm>. Acesso em: 27 out. 2007.

WELCH, C. L.; WELCH, D. E.; HEWERDINE, L. Gender and export behavior: evidence from women-owned enterprises. Journal of Business Ethics, Dordrecht, v. 83, n. 1, p. 113126, 2008.

WELTER, F. et al. Social capital and women entrepreneurship in fragile environments: does networking matter? Frontiers of Entrepreneurship Research, 2004. Disponível em: <http://www. babson.edu >. Acesso em: 24 out. 2007.

WHITE, B.; COX, C. A comparison of the characteristics of female managers and female entrepreneurs. Women in Management Review, Bradford, v. 6, n. 2, 1991.

WILKENS, J. A Mulher Empreendedora: como iniciar o seu próprio negócio. São Paulo: Mc-Graw-Hill, 1989.

WILSON, F.; KICKUL, J.; MARLINO, D. Gender, entrepreneurial self-efficacy, and entrepreneurial career intentions. Entrepreneurship Theory and Practice, [S. 1.], v. 31, n. 3, p. 387406, May 2007.

; et al. Bank loan officers' perceptions of business owners: the role of gender. British Journal of Management, Oxford, v. 18, n. 2, p. 154-171, 2007.

WINN, J. Women entrepreneurs: can we remove the barriers? International Entrepreneurship and Management Journal, Heidelberg, v.1, n. 3, p. 381-397, Sept. 2005.

ZAPALSKA, A. A profile of woman entrepreneurs and enterprises in Poland. Journal of Small Business Management. Morgantown, v. 35, n. 4, p. 76-83, Oct. 1997. 